\title{
Molecular complexes theoretical computations between methanol and carbon dioxide and their implications in the interstellar ice mantles
}

\author{
A. Klotz ${ }^{1,2}$, T. Ward ${ }^{2}$, and E. Dartois ${ }^{3}$ \\ ${ }^{1}$ Centre d'Étude Spatiale des Rayonnements, Observatoire Midi-Pyrénées (CNRS-UPS), BP 4346, \\ 31028 Toulouse Cedex 04, France \\ 2 Laboratoire de Physique Quantique, Institut de Recherche sur les Systèmes Atomiques et Moléculaires Complexes \\ (UPS-CNRS), 118 Route de Narbonne, 31400 Toulouse, France \\ 3 Institut d'Astrophysique Spatiale (CNRS), Orsay, France
}

Received 21 May 2003 / Accepted 7 November 2003

\begin{abstract}
Theoretical computations were carried out on the molecular complex between methanol and carbon dioxide. These calculations explain the broadening of the $15 \mu \mathrm{m}$ spectral feature observed in interstellar ices. This feature is assigned to the bending of $\mathrm{C}-\mathrm{O}$ of the carbon dioxide and we confirm that the broadening is compatible with methanol interactions of the electron donor acceptor type. Extra interactions are also investigated and can be implied in the broadening.
\end{abstract}

Key words. molecular: spectroscopy infrared

\section{Introduction}

Infrared Space Observatory (ISO) results led to new discoveries concerning the composition of ice mantles in dense molecular clouds. Water-ice is usually the most abundant component and is observed by the bands at $3 \mu \mathrm{m}$ (OH stretch), $6 \mu \mathrm{m}$ (OH bend) and, with more difficulty, via the libration mode at $13.5 \mu \mathrm{m}$ (Cox 1989). The less abundant constituents detected prior to ISO were $\mathrm{CO}, \mathrm{CH}_{3} \mathrm{OH}$ and $\mathrm{CH}_{4}$ (identified as the most likely carriers of the general hydrocarbon stretches observed). One of the major discoveries of ISO was the ubiquitous presence of $\mathrm{CO}_{2}$ in protostellar environments, with relatively high abundance (12-20\% with respect to water-ice). This was confirmed through the strong stretching mode of $\mathrm{CO}_{2}$ observed in different interstellar environments at $4.27 \mu \mathrm{m}$ (de Graauw et al. 1996). In addition, solid $\mathrm{CH}_{4}(1.4-4 \%)$, and OCS (0.04$0.2 \%$ ) were observed as minor solid components of the ice (Ehrenfreund et al. 1999).

\subsection{Circumstellar ices}

The infrared spectra of the circumstellar environments of massive protostars such as RAFGL 7009 and/or W33 A represent unique opportunities for the detection of weak solid state environments, due to the high column densities of solid matter in their lines of sight. Consequently, it has proved instructive to compare the spectra from these objects with some of

Send offprint requests to: A. Klotz, e-mail: klotz@cesr.fr the weaker bands which are commonly observed in laboratory simulations of interstellar ices. Solid-state features observed towards the Young Stellar Object (YSO) RAFGL7009 with ISO-SWS included $\mathrm{H}_{2} \mathrm{O}, \mathrm{CO},{ }^{12} \mathrm{CO}_{2},{ }^{13} \mathrm{CO}_{2}$ and $\mathrm{CH}_{4}$ (d'Hendecourt et al. 1996). In addition, there were bands at 4.9 and $6.85 \mu \mathrm{m}$ whose origin is yet to be unambiguously identified, although methanol modes are thought to contribute strongly to both. The presence of small quantities of $\mathrm{H}_{2} \mathrm{CO}$ and OCS was also proposed by overall identification with laboratory spectra of UV irradiated ices (d'Hendecourt et al. 1996).

\subsection{Methanol in ices}

Dartois et al. (1999a) presented ground-based $L$-band spectrum of RAFGL 7009S and of another high-mass protostar W33A. They found that methanol was in fact the second most abundant molecule in both of these lines of sight, seen via its $v_{3}$ $\mathrm{CH}_{3}$ symmetric stretch $(3.54 \mu \mathrm{m})$, combination modes (3.84 and $3.94 \mu \mathrm{m})$ and $\mathrm{CH}_{3}$ deformation $(6.85 \mu \mathrm{m})$. After subtraction of the saturated silicate absorption, the $\mathrm{CH}_{3} \operatorname{rock}(8.9 \mu \mathrm{m})$ and $\mathrm{CO}$ stretch $(9.7 \mu \mathrm{m})$ were also seen. The abundance of methanol was found to be $30 \%$ with respect to water in RAFGL 7009S and 5-22\% in W33A. The fact that the profiles of absorption features were similar suggested that the methanol was in similar ice environments in both sources. Methanol has been observed towards high-mass protostars and the non-detection towards field stars and low-mass protostars in the Taurus dense cloud at $3.54 \mu \mathrm{m}$, gives an upper limit to the abundance of 2-7\% (Dartois et al. 1999a; Chiar et al. 1996). However, 


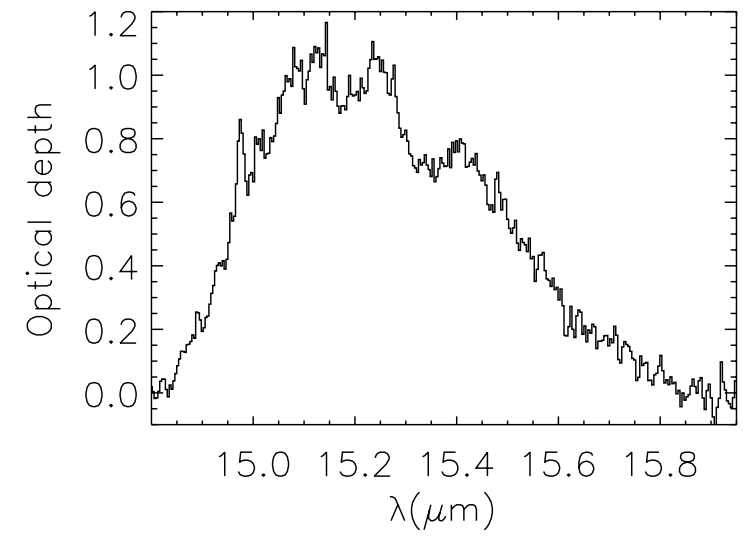

Fig. 1. Observed splitting of the $\mathrm{CO}_{2}$ bending mode at $15.2 \mu \mathrm{m}$ (Dartois et al. 1999b).

recent observations using the ISAAC-VLT spectrometer allowed the detection of solid methanol around low-mass stars in the Serpens cloud (Pontoppidan et al. 2003), which will shed light on the formation mechanism differences with the Taurus cloud when the particular clouds environments are better understood.

\subsection{Ice segregation}

Ehrenfreund et al. (1998) discussed a schematic evolution of circumstellar grains. In protostar envelopes, far from hot cores $(T<20 \mathrm{~K})$ grains are assumed to be covered by apolar ice mantles resulting from molecular accretion dominated by CO. Under apolar mantles, a polar ice layer should be dominated by water ices. As apolar mantles sublimate $(T \simeq 50 \mathrm{~K})$ minor compounds $\left(\mathrm{CH}_{3} \mathrm{OH}, \mathrm{CO}_{2}, \mathrm{CH}_{4}\right.$ and $\left.\mathrm{NH}_{3}\right)$ are processed and the sublimation of the most volatile molecules leads to ices mainly dominated by $\mathrm{H}_{2} \mathrm{O}, \mathrm{CO}_{2}$ and $\mathrm{CH}_{3} \mathrm{OH}$ for temperatures between 50 and $90 \mathrm{~K}$. Above about $90 \mathrm{~K}$, naked mineral cores are released, eventually covered by a refractive residue produced by the irradiation of the ices mantles before their sublimation. This scenario ties in neatly with some of the observations of RAFGL 7009 S that have already been discussed.

\subsection{The $15.2 \mu \mathrm{m}$ feature}

Interestingly, various ISO observations show that the $v_{2}$ bending mode of $\mathrm{CO}_{2}$ at $15.2 \mu \mathrm{m}$ exhibits specific splitting patterns which vary significantly from source to source and can exhibit two or three distinct components at about 15.1, 15.25 and $15.4 \mu \mathrm{m}$ (Dartois et al. 1999b).

Early explanations for these unusual features centred around absorption from other molecules coinciding with this band. Formic acid was put forward as a possible candidate because the $v_{9}$ mode of this molecule falls in a similar region of the spectra. However, this possibility had to be discounted due to the absence of other signature modes, in particular the $\mathrm{CO}$ stretch at $1700 \mathrm{~cm}^{-1}$, which one would expect to see strongly if formic acid was present with an abundance compatible with the $15.2 \mu \mathrm{m}$ feature (Dartois et al. 1999b). A second possibility was that the observed multi-peak structure could be a result of grain size and shape effects. Previously, Bohren et al. (1983) had hypothesised that if interstellar grains were needle shaped then this could cause an asymmetry in some of the bands and possibly even give rise to new features. This can be discounted for two reasons: i) $15.2 \mu \mathrm{m}$ is far greater than the typical grain radii and as such no strong scattering effects should be observed, ii) the $\mathrm{CO}_{2}$ stretching modes and other solid state absorption appear unaffected (Dartois et al. 1998) whereas a scattering effect, if present, should affect most of the observed modes (e.g. Baratta et al. 2000, Fig. 7). This leads to the conclusion that there is something "unique" about this particular bending mode of $\mathrm{CO}_{2}$.

\subsection{Molecular interactions with $\mathrm{CO}_{2}$}

The carbon atom in $\mathrm{CO}_{2}$ can act as a Lewis acid because part of its electron density is removed due to the two electronegative $\mathrm{O}$ atoms. Consequently, molecules containing at least one lone pair can form an Electron Donor Acceptor (EDA) complex via a long-range molecular interaction with the carbon atom (Kazarian et al. 1996). As this interaction takes place through the carbon and the two $\mathrm{O}$ atoms are repelled, the strength of the intramolecular bonds is affected and the bond angle is deformed from its linear geometry. This obviously affects the IR spectrum of $\mathrm{CO}_{2}$, which has become of astronomic interest since ISO revealed the presence of $\mathrm{CO}_{2}$ in the spectra of many protostellar sources. The first and most obvious observable effect is the breaking of the degeneracy of the $v_{2}$ bending mode which causes it to initially split into two. This effect will be discussed in more detail in Sect. 2.3, which deals with theoretical calculations of the complex between $\mathrm{CO}_{2}$ and methanol.

\subsection{Contribution of laboratory spectra}

Various experiments (Ehrenfreund et al. 1998; Palumbo et al. 1998; Dartois et al. 1999b) show the triple splitting of the $v_{2}$ bending mode of $\mathrm{CO}_{2}$ in ice mixtures using the technique of matrix spectroscopy, whereby gas mixtures are slowly deposited onto a cold (4-100 K) CsI window and IR spectra are recorded. For an explanation of this technique the reader is directed to Allamandola (1987). Experiments show only marginal splittings when alcohols were replaced by $\mathrm{H}_{2} \mathrm{O}$, $\mathrm{HCOOH}$ or $\mathrm{NH}_{3}$.

In conclusion, Dartois et al. (1999b) proved that a stable physical complex between methanol and $\mathrm{CO}_{2}$ can form and that these intermolecular interactions, in a physically segregated mantle, will influence the $15.2 \mu \mathrm{m}$ line shape. Although the observed substructure can be reproduced in the laboratory with ethanol mixtures, methanol is undoubtedly the astrophysical candidate. This explanation was reinforced by the UKIRT observations towards RAFGL 7009S and W33A, which showed that methanol is the second most abundant molecule after water in these two similar sources (Dartois et al. 1999a).

This paper attempts to elucidate the astrophysical spectral feature near $15.2 \mu \mathrm{m}$ using theoretical computational methods to reproduce the molecular environment of interstellar ices. 
Table 1. Calculated molecular and spectroscopic parameters for $\mathrm{CO}_{2}: \mathrm{CH}_{3} \mathrm{OH}$ complex from Jamróz et al. (1995) (RHF/3-21G* level). Energy is the stabilization energy of the complex. OOP means "out of plane".

\begin{tabular}{lcccccc}
\hline \hline Geometry & $\begin{array}{c}\text { Energy } \\
\left(\mathrm{kcal} \mathrm{mol}^{-1}\right)\end{array}$ & $\begin{array}{c}\text { Distance } \\
(\AA)\end{array}$ & $\begin{array}{c}\text { Angle } \\
(\mathrm{deg})\end{array}$ & $\begin{array}{c}\text { In plane mode } \\
\left(\mathrm{cm}^{-1}\right)\end{array}$ & $\begin{array}{c}\text { OOP mode } \\
\left(\mathrm{cm}^{-1}\right)\end{array}$ & $\begin{array}{c}\text { Split } \\
\left(\mathrm{cm}^{-1}\right)\end{array}$ \\
\hline Parallel & 8.59 & 2.468 & 174.07 & 676.2 & 652.5 & 23.7 \\
Perpendicular & 6.02 & 2.600 & 174.95 & 673.5 & 652.9 & 20.6 \\
\hline
\end{tabular}

\section{Theoretical computation}

\subsection{Previous studies}

The experimental work in this paper follows one from a paper by Jamróz et al. (1995), which presented ab-initio calculations for various EDA complexes involving $\mathrm{CO}_{2}$. They used the SPARTAN program to investigate the $v_{2}$ modes of $\mathrm{CO}_{2}$ and also presented the stabilisation energies and geometry of the complexes. It was shown that the lone pair of the Donor-atom points towards the $\mathrm{CO}_{2}$ molecule and results in an attraction of the $\mathrm{C}$-atom and a repulsion of the two $\mathrm{O}$-atoms. This results in a bending of the $\mathrm{CO}_{2}$ molecule and the observed splitting is explained in terms of the consequent release of the double degeneracy of the $v_{2}$ mode. The mode at higher frequency is assigned to the out-of-plane (OOP) mode and the other is therefore the in-plane mode. The paper investigated a number of possible donor molecules classified with respect to the Donoratom. These included the $\mathrm{sp}^{3} \mathrm{O}$-atom $\left(\mathrm{H}_{2} \mathrm{O}\right.$, alcohols, ethers $)$, $\mathrm{sp}^{2} \mathrm{O}$-atom (aldehydes and ketones), $\mathrm{sp}^{3} \mathrm{~N}$ (NH3, amines) and sp N (HCN and nitriles). However, the only astrophysically relevant candidate is methanol. Jamróz et al. (1995) investigated two possible approaches for the $\mathrm{CH}_{3} \mathrm{OH}: \mathrm{CO}_{2}$ Complex, which they called perpendicular and parallel and the key results are presented in Table 1. It can be seen that the most stable complex is the so-called "parallel" approach. The perpendicular and parallel approaches correspond to "horizontal" and "vertical" approaches respectively, shown in Fig. 2.

The $\mathrm{CO}_{2}$ molecule is deformed markedly to $174.07^{\circ}$ and this manifests itself in a large calculated splitting of $23.7 \mathrm{~cm}^{-1}$, which is more than twice the experimentally observed value. The method used in this paper was the RHF/3-21G*. However, Hartee-Fock (HF) level is known for its inability to include electron correlation. Jamróz et al. (1995) explain the discrepancy in calculated and experimental splitting as being either due to basis-set inadequacies or the omission of solvent environment and electron correlation effects. With this in mind the impetus for the experimental work was to carry out calculations for the $\mathrm{CH}_{3} \mathrm{OH}: \mathrm{CO}_{2}$ complex with methods that deal with the electron correlation problem.

\subsection{Method and basis set}

The calculations were started by treating the $\mathrm{CO}_{2}$ and methanol independently, which allowed the effectiveness of different basis sets and methods to be compared. In this way, the complex (which includes more nuclear centres and is therefore more computationally demanding) could be investigated using methods that were likely to yield frequencies in the range

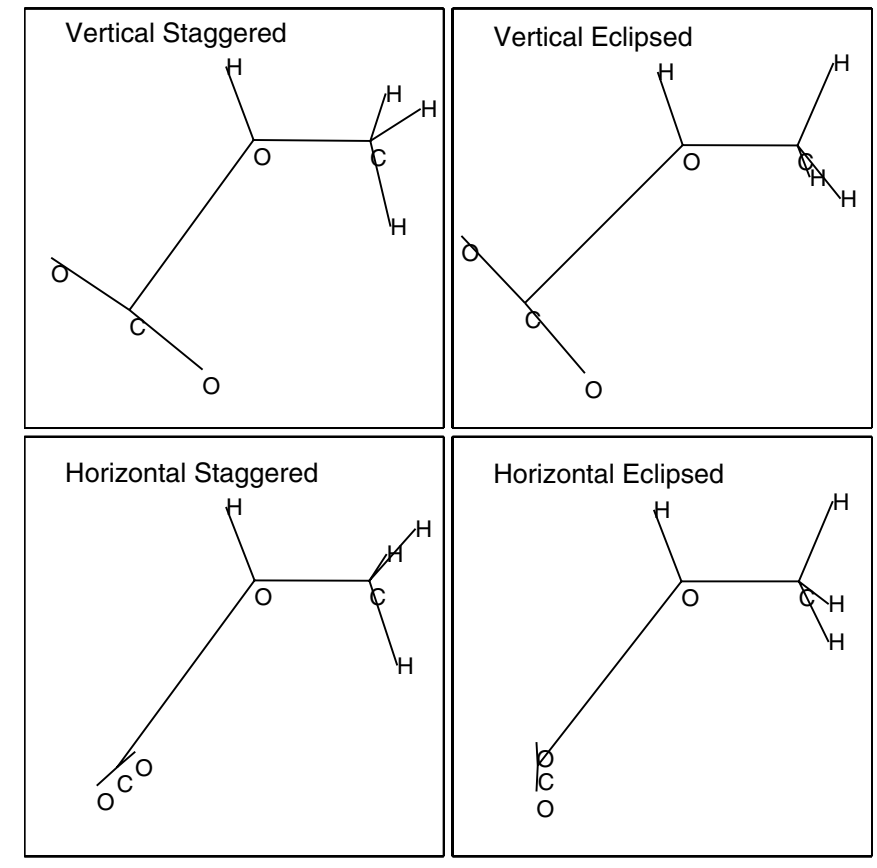

Fig. 2. Stick representation of the four possible conformations of the complex: top-left: "vertical staggered", top-right: "vertical Eclipsed", bottom-left: "horizontal staggered", bottom-right: "horizontal eclipsed". The staggered/eclipsed conformations are defined relative to methanol hydrogens. Eclipsed means that the alcoholic hydrogen lies in the plane defined by the methanol $\mathrm{CO}$ and one of the three methylic hydrogens. Staggered conformations occur after rotations of $\pi / 3$ from the eclipsed conformations of the methyl group.

of the astrophysical spectra. In the following calculations, the GAUSSIAN98 software (Frisch et al. 1998) was used. Initially RHF calculations were carried out for $\mathrm{CO}_{2}$ using the minimal basis set STO-3G, which consists of expansions of Slater-type atomic orbitals in terms of three Gaussian functions. Again using the $\mathrm{HF}$ method, the $\mathrm{CO}_{2}$ calculations were repeated for the large split-valence representation 6-31G, which is defined through the second row of the Periodic Table. This basis set comprises inner-shell functions written in terms of a linear combination of six Gaussians. In addition there are two valence shells represented by three and one Gaussian primitives respectively. It was found that the RHF/6-31G yielded values for the $\mathrm{CO}_{2}$, which were far closer to the literature values than the STO-3G.

The next step was to use a method that incorporates the effects of electron correlation and it has been mentioned that MP2 calculations are the most efficient way of doing this. 
Table 2. Results of the $\mathrm{CO}_{2}$ calculations (IR intensities in kilometres/mole shown in parentheses). Experimental values are from Lide (1992). OOP means "out of plane".

\begin{tabular}{ccccc}
\hline \hline Method & $\begin{array}{c}\text { Bend (in-plane) } \\
\left(\mathrm{cm}^{-1}\right)\end{array}$ & $\begin{array}{c}\text { Bend (OOP) } \\
\left(\mathrm{cm}^{-1}\right)\end{array}$ & $\begin{array}{c}\text { Stretch (sym) } \\
\left(\mathrm{cm}^{-1}\right)\end{array}$ & $\begin{array}{c}\text { Stretch (antisym) } \\
\left(\mathrm{cm}^{-1}\right)\end{array}$ \\
\hline Experimental & 667 & 667 & 1333 & 2349 \\
RHF/STO-3G & $566.06(34.0)$ & $566.06(34.0)$ & $1435.44(0.0)$ & $2536.18(342.3)$ \\
RHF/6-31G & $656.54(67.2)$ & $656.54(67.2)$ & $1407.50(0.0)$ & $2374.57(918.8)$ \\
MP2/6-31G & $520.42(16.4)$ & $520.42(16.4)$ & $1227.14(0.0)$ & $2292.81(382.9)$ \\
MP2/6-31++G & $451.17(17.3)$ & $451.17(17.3)$ & $1213.84(0.0)$ & $2236.91(507.6)$ \\
MP2/6-31++G* & $655.12(24.7)$ & $655.12(24.7)$ & $1335.54(0.0)$ & $2432.90(603.94)$ \\
MP4/6-31++G & $436.67(0.0)$ & $436.67(0.0)$ & $1095.04(0.0)$ & $2130.88(0.0)$ \\
B3LYP/6-311++G & $540.85(28.27)$ & $540.85(28.27)$ & $1269.74(0.0)$ & $2231.90(580.84)$ \\
B3LYP/6-311++G* & $668.59(33.1)$ & $668.59(33.1)$ & $1372.96(0.0)$ & $2420.02(711.6)$ \\
\hline
\end{tabular}

Table 3. Methanol results for IR active bands with intensity $(\mathrm{km} / \mathrm{mol})$ in parentheses. For the last colmumn, qualitative intensities are reported: $\mathrm{VS}=$ very strong, $\mathrm{S}=$ strong, $\mathrm{M}=$ medium, $\mathrm{W}=$ weak, liq = seen in liquids, $\mathrm{OV}=$ overtone.

\begin{tabular}{|c|c|c|c|c|c|}
\hline Assignment & $\begin{array}{c}\text { MP2 } \\
6-311++G^{*}\end{array}$ & $\begin{array}{c}\text { MP2 } \\
6-311++\mathrm{G}^{* *}\end{array}$ & $\begin{array}{c}\text { B3LYP } \\
6-311++G^{*}\end{array}$ & $\begin{array}{c}\text { B3LYP } \\
6-311++\mathrm{G}^{* *}\end{array}$ & Experimental \\
\hline Torsion & $324.12(160.2)$ & $311.54(131.4)$ & 313.24 (154.6) & $297.16(134.7)$ & 295 \\
\hline$\nu \mathrm{CO}$ & $1075.05(125.4)$ & $1074.89(119.5)$ & $1047.66(133.1)$ & $1041.68(128.2)$ & 1033 (VS) \\
\hline $\mathrm{CH}_{3}$ rock & $1088.66(8.0)$ & $1096.56(2.5)$ & $1070.55(3.0)$ & $1070.36(1.1)$ & $1060(\mathrm{~W})$ \\
\hline $\mathrm{CH}_{3}$ rock & $1196.08(0.4)$ & $1195.13(0.6)$ & $1175.18(0.4)$ & $1167.45(0.2)$ & 1165 (liq) \\
\hline$\delta \mathrm{OH}$ & $1386.47(23.5)$ & $1379.54(19.1)$ & $1367.88(23.9)$ & 1356.19 (20.9) & $1345(\mathrm{~S})$ \\
\hline$\delta \mathrm{CH}$ & $1518.71(4.3)$ & $1508.41(6.7)$ & $1490.55(5.3)$ & $1479.56(5.1)$ & $1455(\mathrm{M})$ \\
\hline$\delta \mathrm{CH}$ & $1536.43(3.8)$ & $1517.24(2.6)$ & $1509.42(3.3)$ & $1493.48(3.3)$ & 1477 (M) \\
\hline$\delta \mathrm{CH}$ & $1547.70(5.4)$ & $1532.75(4.4)$ & $1520.51(5.1)$ & $1505.00(5.1)$ & $1477(\mathrm{OV})(\mathrm{M})$ \\
\hline$v \mathrm{CH}_{3}(\mathrm{Sym})$ & $3056.76(60.4)$ & $3055.24(58.8)$ & $2994.31(74.2)$ & $2990.00(68.2)$ & $2844(\mathrm{~S})$ \\
\hline$v \mathrm{CH}_{2}$ (Asym) & $3128.49(53.9)$ & $3125.13(52.5)$ & $3041.81(72.3)$ & $3037.48(63.6)$ & $2960(\mathrm{~S})$ \\
\hline $v \mathrm{CH}($ Asym) & $3202.85(23.1)$ & $3190.33(24.0)$ & $3125.40(30.6)$ & $3112.85(27.3)$ & $3000(\mathrm{M})$ \\
\hline$v \mathrm{OH}$ & $3848.98(21.5)$ & $3913.81(36.1)$ & $3789.46(12.4)$ & $3847.26(30.0)$ & $3681(\mathrm{M})$ \\
\hline
\end{tabular}

However, the MP2/6-31G method gave results that were further away from the experimental values than the corresponding HF method. The only explanation for this was that the basis set was ineffective for the MP2 calculations. With this in mind, the effect of extending the basis set was investigated. Additions of diffuse functions to the basis set were tested using the MP2/6$31++\mathrm{G}$ methods but once more the results were disappointing. However, the use of MP2/6-31++G* (which includes extra $\mathrm{d}$ polarisation functions on each atom), saw a good correlation with experimental $\mathrm{CO}_{2}$ frequencies.

We tested also the hybrid density functional method, Becke's three-parameter non-local exchange functional (Becke 1992) with the non-local correlation functional of Lee et al. (1988) (hereafter B3LYP). B3LYP method was tested with both the $6-311++\mathrm{G}$ and $6-311++\mathrm{G}^{*}$ basis and the latter reproduced the experimental values (Lide 1992) remarkably well. The results of the calculations are shown in Table 2. The same process of investigation was repeated for a "staggered" methanol molecule and the following calculations were carried out: RHF (STO-3G, 6-31G), MP2 (6-311++G,
6-311++G*, 6-311++G**), B3LYP $\left(6-311++\mathrm{G}, 6-311++\mathrm{G}^{*}\right.$, $\left.6-311++\mathrm{G}^{* *}\right)$. The staggered and eclipsed molecules are shown in Fig. 2. It is important to note that, for $\mathrm{CO}_{2}$, the $6-311++\mathrm{G}^{*}$ and $6-311++\mathrm{G}^{* *}$ methods are identical as the extra star simply represents added polarisation functions on $\mathrm{H}$-atoms and is therefore obsolete for the $\mathrm{CO}_{2}$ molecule. The calculations were repeated with methanol in an "eclipsed" conformation and it was found that the staggered is the preferred (i.e. lower energy) conformation as one would expect (see Table 3). As a result of the monomer calculations it was decided that $6-311++\mathrm{G}^{*}(*)$ was a good basis set with which to run the complex calculations and that B3LYP was the preferred method.

\section{3. $\mathrm{CO}_{2}: \mathrm{CH}_{3} \mathrm{OH}$ complex}

Figure 2 shows the four possible conformations for the EDA complex. Calculations were carried out for these using MP2 and B3LYP methods together with the $6-311++\mathrm{G}^{*}$ basis set. 
Table 4. Mulliken analysis of charges comparing the "vertical staggered" complex with the isolated molecules.

\begin{tabular}{ccccccc}
\hline \hline & $\begin{array}{c}\mathrm{C} \\
(\mathrm{meth})\end{array}$ & $\begin{array}{c}\mathrm{O} \\
(\mathrm{meth})\end{array}$ & $\begin{array}{c}\mathrm{H} \\
(\mathrm{OH})\end{array}$ & $\begin{array}{c}\mathrm{C} \\
\left(\mathrm{CO}_{2}\right)\end{array}$ & $\begin{array}{c}\mathrm{O} 1 \\
\left(\mathrm{CO}_{2}\right)\end{array}$ & $\begin{array}{c}\mathrm{O} 2 \\
\left(\mathrm{CO}_{2}\right)\end{array}$ \\
\hline Monomer & -0.5918 & -0.4181 & +0.3580 & +0.4636 & -0.2318 & -0.2318 \\
Complex & -0.6086 & -0.4208 & +0.3549 & +0.4826 & -0.2415 & -0.2381 \\
\hline
\end{tabular}

Table 5. Comparison of bond lengths for monomer and "vertical staggered" $\mathrm{CO}_{2}: \mathrm{CH}_{3} \mathrm{OH}$ complex.

\begin{tabular}{lcc}
\hline \hline B3LYP/6-311++G** & $\begin{array}{c}\text { Monomer } \\
(\AA)\end{array}$ & $\begin{array}{c}\text { Complex } \\
(\AA)\end{array}$ \\
\hline Methanol C-O & 1.4220 & 1.4266 \\
Methanol O-H & 0.9594 & 0.9615 \\
Methanol C-H (ip) & 1.0899 & 1.0898 \\
2 Methanol C-H (oop) & 1.0959 & 1.0960 \\
\hline Intermolecular & NA & 2.7548 \\
\hline $\mathrm{CO}_{2} \mathrm{C}-\mathrm{O}$ & 1.1608 & 1.1611 \\
$\mathrm{CO}_{2} \mathrm{C}-\mathrm{O}$ & 1.1608 & 1.1610 \\
\hline
\end{tabular}

In order to calculate vibrational frequencies with the GAUSSIAN98 program it is first necessary to optimise the geometry of any molecule or complex. For the "horizontal approach", the two $\mathrm{CO}_{2}$ bond lengths were constrained to be equal. However, with the "vertical approach" each $\mathrm{O}$ is in a slightly different environment and they were permitted to be different. For both approaches the angles formed between each $\mathrm{CO}_{2}$ bond and the Lewis acid bond were again permitted to be different. The main difference between the inputted $Z$-matrix for the two approaches were the dihedral angles between the $\mathrm{CO}_{2}$ oxygen atoms and the plane of the methanol molecule. For the "vertical" approaches one $\mathrm{O}$ had a dihedral angle of $0^{\circ}$ and the other was at $180^{\circ}$, whereas the dihedral angles for the "horizontal" approaches were $\pm 90^{\circ}$. The change in bond lengths for the "vertical staggered" approach are shown in Table 5, which shows the slightly different $\mathrm{CO}_{2}$ bond lengths.

In the calculations it was seen that very little charge transfer is observed for the complex compared to the individual monomers (see Table 4). This is again to be expected as an electrostatic interaction is being proposed rather than the formation of a new molecule.

Table 6 shows the stabilisation energies and important geometric properties for the calculations. It can be seen that the distance of interaction is long (around $2.7 \AA$ for the "staggered approaches"), and this is expected for such a Van der Waals complex. In addition, the deformation in the $\mathrm{CO}_{2}$ bond angle is shown. This relates to the bond distance because the shorter the distance, the stronger the interaction and hence the more the $\mathrm{CO}_{2}$ will be bent. It can be seen that the bond distance and binding energies correlate correctly i.e. the shorter the bond distance the stronger the interaction and hence the larger the binding energy.

Comparing the results of Table 6 to those of Jamróz et al. (1995) (Table 1) it can be seen that our results give longer

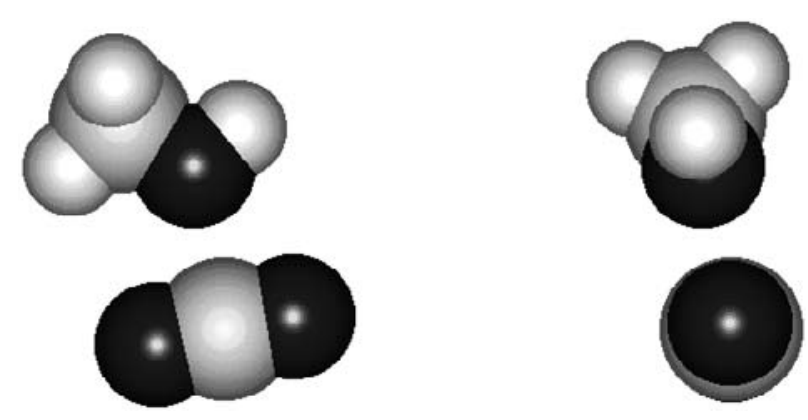

Fig. 3. Ball representation of the most stable conformer of $\mathrm{CO}_{2}: \mathrm{CH}_{3} \mathrm{OH}$ complex (face on and edge on views).

distances and smaller binding energies. This is explained because the basis set used by Jamróz et al. was inadequate and suffered from Basis Set Superposition Effects (BSSE). This is where each monomer uses functions, which are not unused by the other monomer, resulting in an exaggerated binding energy. The larger intermolecular distances and consequent smaller binding energies can be seen as a validation of the use of larger basis sets. It can be seen that the "vertical staggered" approach has the largest stabilisation energies for the respective methods and is therefore the most likely geometry to occur in IS ices. The subsequent discussion will therefore be centred on this conformer.

\section{Vibrational analysis}

\section{1. $\mathrm{CO}_{2}$ :methanol interactions}

The vibrational frequencies were calculated for each of the four conformers with the B3LYP and MP2 methods, with 6$311++\mathrm{G}^{*}$ chosen as the basis set due to the success seen for the monomer calculations. For the "horizontal staggered" and both "eclipsed" approaches, negative frequencies were observed. These negative frequencies represent "saddle points" on the potential energy curve and therefore these conformations do not represent true minima. For the conformers where methanol is eclipsed it was possible to assign the negative frequencies at around $-300 \mathrm{~cm}^{-1}$ to a rotation of the methyl group back to the preferred staggered conformation. This is possible because the GAUSSIAN98 output provides information on which atoms are giving rise to each vibrational frequency. The B3LYP/6-311++G* calculation for the "vertical staggered" approach does not produce any negative frequencies and as such this conformer is the true minimum. (This is further confirmation of the inference made due to the larger binding energy for this approach.) Consequently, the experiment for this method and geometry was repeated with the $6-311++\mathrm{G}^{* *}$ basis set to see the effect of adding extra polarisation functions to the 
Table 6. Stabilisation energy and important geometric properties for the $\mathrm{CO}_{2}: \mathrm{CH}_{3} \mathrm{OH}$ complexes. Intensities $\left(\mathrm{km} \mathrm{mol}^{-1}\right)$ are in parentheses.

\begin{tabular}{ccccccc}
\hline \hline & $\begin{array}{c}\text { Distance } \\
(\AA)\end{array}$ & $\begin{array}{c}\text { Angle } \\
(\mathrm{deg})\end{array}$ & $\begin{array}{c}\text { Energy } \\
\left(\mathrm{kcal} \mathrm{mol}^{-1}\right)\end{array}$ & $\begin{array}{c}\text { In plane mode } \\
\left(\mathrm{cm}^{-1}\right)\end{array}$ & $\begin{array}{c}\text { OOP mode } \\
\left(\mathrm{cm}^{-1}\right)\end{array}$ & $\begin{array}{c}\text { Split } \\
\left(\mathrm{cm}^{-1}\right)\end{array}$ \\
\hline Vertical staggered & & & & & & \\
B3LYP/6-311++G** & 2.7548 & 177.33 & 2.66 & $651.36(64.0)$ & $672.77(33.1)$ & 21.41 \\
B3LYP/6-311++G* & 2.7074 & 177.01 & 3.05 & $649.16(67.1)$ & $673.41(34.1)$ & 24.25 \\
MP2/6-311++G* & 2.6712 & 177.26 & 4.58 & $639.65(49.2)$ & $661.40(25.5)$ & 21.75 \\
\hline Horizontal staggered & & & & & & \\
B3LYP/6-311++G* & 2.9154 & 177.81 & 1.70 & $654.32(56.1)$ & $673.47(29.8)$ & 19.15 \\
MP2/6-311++G* & 2.8237 & 177.86 & 3.03 & $638.79(42.9)$ & $661.05(22.2)$ & 22.26 \\
\hline Vertical eclipsed & & & & & \\
B3LYP/6-311++G* & 2.7180 & 177.05 & 2.99 & $649.03(66.9)$ & $673.39(33.58)$ & 24.36 \\
MP2/6-311++G* & 2.6794 & 177.28 & 4.42 & $638.91(49.3)$ & $661.78(25.4)$ & 22.87 \\
\hline Horizontal eclipsed & & & & & \\
B3LYP/6-311++G* & 2.9010 & 177.73 & 1.81 & $653.77(56.6)$ & $673.46(29.9)$ & 19.69 \\
MP2/6-311++G* & 2.8124 & 177.84 & 3.14 & $638.69(42.5)$ & $660.74(22.6)$ & 22.05 \\
\hline
\end{tabular}

Table 7. Comparison of the calculated frequencies of the "vertical staggered" $\mathrm{CO}_{2}: \mathrm{CH}_{3} \mathrm{OH}$ complex with those of the monomers (calculated and experimental). Experimental values for methanol were measured by the authors with the aparatus described in Dartois et al. (1999b). Calculated intensities $\left(\mathrm{km} \mathrm{mol}^{-1}\right)$ are in parentheses. Qualitative experimental intensities are: VS = very strong, $\mathrm{S}=\mathrm{strong}, \mathrm{M}=\mathrm{medium}$, $\mathrm{W}=$ weak, liq $=$ seen in liquids, $\mathrm{OV}=$ overtone.

\begin{tabular}{|c|c|c|c|c|c|}
\hline & $\begin{array}{c}\text { B3LYP } \\
6-311++G^{*}\end{array}$ & $\begin{array}{l}\text { Calculated } \\
\text { Isolated (*) }\end{array}$ & $\begin{array}{c}\text { B3LYP } \\
6-311++G^{* *}\end{array}$ & $\begin{array}{c}\text { Calculated } \\
\text { Isolated }(* *)\end{array}$ & $\begin{array}{c}\text { Experimental } \\
\text { Isolated }\end{array}$ \\
\hline & $25.96(13.6)$ & & $24.11(12.2)$ & & \\
\hline Complex & $40.41(2.3)$ & & $37.06(2.2)$ & & \\
\hline Specific & $78.82(12.0)$ & & $75.42(10.4)$ & & \\
\hline \multirow[t]{2}{*}{ Bands: } & $105.92(0.7)$ & & $98.62(0.8)$ & & \\
\hline & $157.34(0.4)$ & & $148.79(0.6)$ & & \\
\hline Torsion & $322.38(143.8)$ & $313.24(154.6)$ & $310.33(128.2)$ & $297.16(134.7)$ & 295 (gas) \\
\hline $\mathrm{CO}_{2}$ in plane & $649.16(67.1)$ & $668.59(33.1)$ & $651.36(64.0)$ & $668.59(33.1)$ & 667 \\
\hline $\mathrm{CO}_{2} \mathrm{OOP}$ & $673.41(34.1)$ & $668.59(33.1)$ & $672.77(33.1)$ & $668.59(33.1)$ & 667 \\
\hline$v \mathrm{CO}$ & $1050.56(116.3)$ & $1047.66(133.1)$ & $1043.50(117.1)$ & $1041.68(128.2)$ & 1033 (VS) \\
\hline $\mathrm{CH}_{3}$ rock & $1074.60(15.2)$ & $1070.55(3.0)$ & $1069.96(7.1)$ & $1070.36(1.1)$ & $1060(\mathrm{~W})$ \\
\hline $\mathrm{CH}_{3}$ rock & $1177.65(0.5)$ & $1175.18(0.4)$ & $1169.18(0.3)$ & $1167.45(0.2)$ & 1165 (liq) \\
\hline$\delta \mathrm{OH}$ & $1369.53(10.2)$ & $1367.88(23.9)$ & $1356.55(17.0)$ & $1356.19(20.9)$ & $1345(\mathrm{~S})$ \\
\hline $\mathrm{CO}_{2}$ str. (sym) & $1372.53(13.1)$ & $1372.96(0.0)$ & $1371.83(1.1)$ & $1372.96(0.0)$ & 1333 (sym) \\
\hline$\delta \mathrm{CH}$ & $1488.06(3.3)$ & $1490.55(5.3)$ & $1477.58(2.6)$ & $1479.56(5.1)$ & $1455(\mathrm{M})$ \\
\hline$\delta \mathrm{CH}$ & $1512.65(3.7)$ & $1509.42(3.3)$ & $1497.15(3.6)$ & $1493.48(3.3)$ & $1477(\mathrm{M})$ \\
\hline$\delta \mathrm{CH}$ & 1522.65 (6.6) & $1520.51(5.1)$ & $1506.87(6.3)$ & $1505.00(5.1)$ & $1477(\mathrm{M})(\mathrm{OV})$ \\
\hline $\mathrm{CO}_{2}$ str. (anti) & $2417.68(664.3)$ & $2420.02(711.6)$ & $2418.36(663.7)$ & $2420.02(711.6)$ & 2349 (anti) \\
\hline$v \mathrm{CH}_{3}(\mathrm{Sym})$ & $3004.65(71.5)$ & $2994.31(74.2)$ & $2998.95(65.8)$ & $2990.00(68.2)$ & $2844(\mathrm{~S})$ \\
\hline$\nu \mathrm{CH}_{2}$ (Asym) & $3056.47(61.0)$ & $3041.81(72.3)$ & $3050.46(54.0)$ & $3037.48(63.6)$ & $2960(\mathrm{~S})$ \\
\hline vCH (Asym) & $3123.63(22.3)$ & $3125.40(30.6)$ & 3121.37 (19.1) & $3112.85(27.3)$ & $3000(\mathrm{M})$ \\
\hline$v \mathrm{OH}$ & $3798.69(19.6)$ & $3789.46(12.4)$ & $3848.97(37.8)$ & $3847.26(30.0)$ & $3681(\mathrm{M})$ \\
\hline
\end{tabular}

H-atom. The full frequency results for the "staggered vertical" approach are shown in Table 7, along with the values calculated for the isolated monomers (with the B3LYP/6-311++G** method).
Table 7 shows that predicted IR intensity of $1372.53 \mathrm{~cm}^{-1}$ band with the $6-311++\mathrm{G}^{*}$ basis is ten times higher that the same computed $b$ with the $6-311++\mathrm{G}^{* *}$ basis. We suggest that this is due to the non equivalent role of oxygens of the 
Table 8. Geometric properties for the two dimers using the B3LYP/6$311++\mathrm{G}^{*}$ (Numbers 1 and 2 in parentheses represent two $\mathrm{CO}_{2}$ molecules).

\begin{tabular}{|c|c|c|}
\hline & "Slipped" & "Constrained linear" \\
\hline \multicolumn{3}{|l|}{ Distances $(\AA)$ : } \\
\hline C-O (1) & 1.1613 & 1.1606 \\
\hline $\mathrm{C}-\mathrm{O}(1)$ & 1.1602 & 1.1606 \\
\hline $\mathrm{C}-\mathrm{O}(2)$ & 1.1616 & 1.1608 \\
\hline $\mathrm{C}-\mathrm{O}(2)$ & 1.1598 & 1.1608 \\
\hline Intermolecular & 3.1828 & 3.1884 \\
\hline \multicolumn{3}{|l|}{ Angles (degrees): } \\
\hline $\mathrm{O}(1) \mathrm{C}(1) \mathrm{O}(2)$ & 84.1 & 90.0 \\
\hline $\mathrm{C}(2) \mathrm{O}(2) \mathrm{C}(1)$ & 138.5 & 180.0 \\
\hline $\begin{array}{c}\text { HF Energies } \\
\text { (Atomic Units) }\end{array}$ & -377.2947 & -377.2946 \\
\hline
\end{tabular}

vertical $\mathrm{CO}_{2}$. Only a very complete basis (as $6-311++\mathrm{G}^{* *}$ ) can describe the long distances interactions correctly.

\section{2. $\mathrm{CO}_{2}: \mathrm{CO}_{2}$ interactions}

The frequencies for two possible carbon dioxide dimers were calculated using the $6-311++\mathrm{G}^{*}$ basis set and both MP2 and B3LYP methods. These two dimers were called "slipped" and "constrained linear". In the "constrained linear" conformer, the $\mathrm{O}$ of one $\mathrm{CO}_{2}$ was made to approach the $\mathrm{C}$ of the other at $90^{\circ}\left(\mathrm{C}_{2 \mathrm{~V}}\right.$ point group). In the "slipped" dimer the two $\mathrm{CO}_{2}$ molecules were placed in a loose lattice structure with the $\mathrm{C}-\mathrm{O}$ bond lengths not constrained to be equal for both $\mathrm{CO}_{2}$ molecules $\left(\mathrm{C}_{\mathrm{S}}\right.$ point group). The key results are shown in Table 8. Table 9 shows the results of the B3LYP frequency calculations for the two dimers together with the binding energies. It can be seen that, apart from the first four, the frequencies are very similar in both cases. The $-10.78 \mathrm{~cm}^{-1}$ frequency in the "constrained linear" dimer is assigned to a $\mathrm{B}_{2}$ mode and this represents the molecule twisting into the "slipped" dimer. This dimer has a (slightly) larger binding energy and it is therefore the most stable of the two. Anyway, interaction between $\mathrm{CO}_{2}$ molecules leads to splits lower than $5 \mathrm{~cm}^{-1}$. It is important to notice that such split is not enough to explain the large broadening of the spectral feature at $655 \mathrm{~cm}^{-1}$ seen in astrophysical objects.

\section{Astrophysical implications}

\subsection{Complex specific features}

A comparison of the computed complex spectra with the methanol monomer is shown in Fig. 4. It can be seen from this figure and Table 7 that our results indicate five new bands that are not present for the isolated molecules and are therefore specific to the formation of the intermolecular complex, plus one mode of the $\mathrm{CO}_{2}$ molecule activated. Using the B3LYP/6-311++G** results, only the bands at $75.42 \mathrm{~cm}^{-1}\left(10.4 \mathrm{~km} \mathrm{~mol}^{-1}\right)$ and $24.11 \mathrm{~cm}^{-1}\left(12.2 \mathrm{~km} \mathrm{~mol}^{-1}\right)$
Table 9. Vibrational frequencies for the two calculated $\mathrm{CO}_{2}$ dimers (B3LYP/6-311++G*). Calculated intensities $\left(\mathrm{km} \mathrm{mol}^{-1}\right)$ are in parentheses.

\begin{tabular}{|c|c|c|}
\hline & $\begin{array}{c}\text { "Slipped" } \\
\left(\mathrm{cm}^{-1}\right)\end{array}$ & $\begin{array}{c}\text { "Constrained linear' } \\
\left(\mathrm{cm}^{-1}\right)\end{array}$ \\
\hline & $10.63(0.0)$ & $-10.78(0.0)$ \\
\hline & $21.95(0.0)$ & $13.79(0.0)$ \\
\hline & $39.09(0.1)$ & $38.77(0.1)$ \\
\hline & $68.10(0.0)$ & $52.65(0.0)$ \\
\hline & $665.57(48.4)$ & $665.89(47.6)$ \\
\hline & $667.45(1.2)$ & $666.17(31.3)$ \\
\hline & $667.88(28.0)$ & $667.70(7.0)$ \\
\hline & $670.01(64.0)$ & $669.88(58.5)$ \\
\hline & $1373.12(0.0)$ & $1373.02(0.0)$ \\
\hline & $1373.68(0.1)$ & $1374.62(0.0)$ \\
\hline & $2420.40(1199.5)$ & $2420.21(689.0)$ \\
\hline & 2421.47 (241.4) & $2422.39(765.2)$ \\
\hline $\begin{array}{c}\text { Energies } \\
\left(\mathrm{kcal} \mathrm{mol}^{-1}\right)\end{array}$ & 0.55 & 0.51 \\
\hline
\end{tabular}
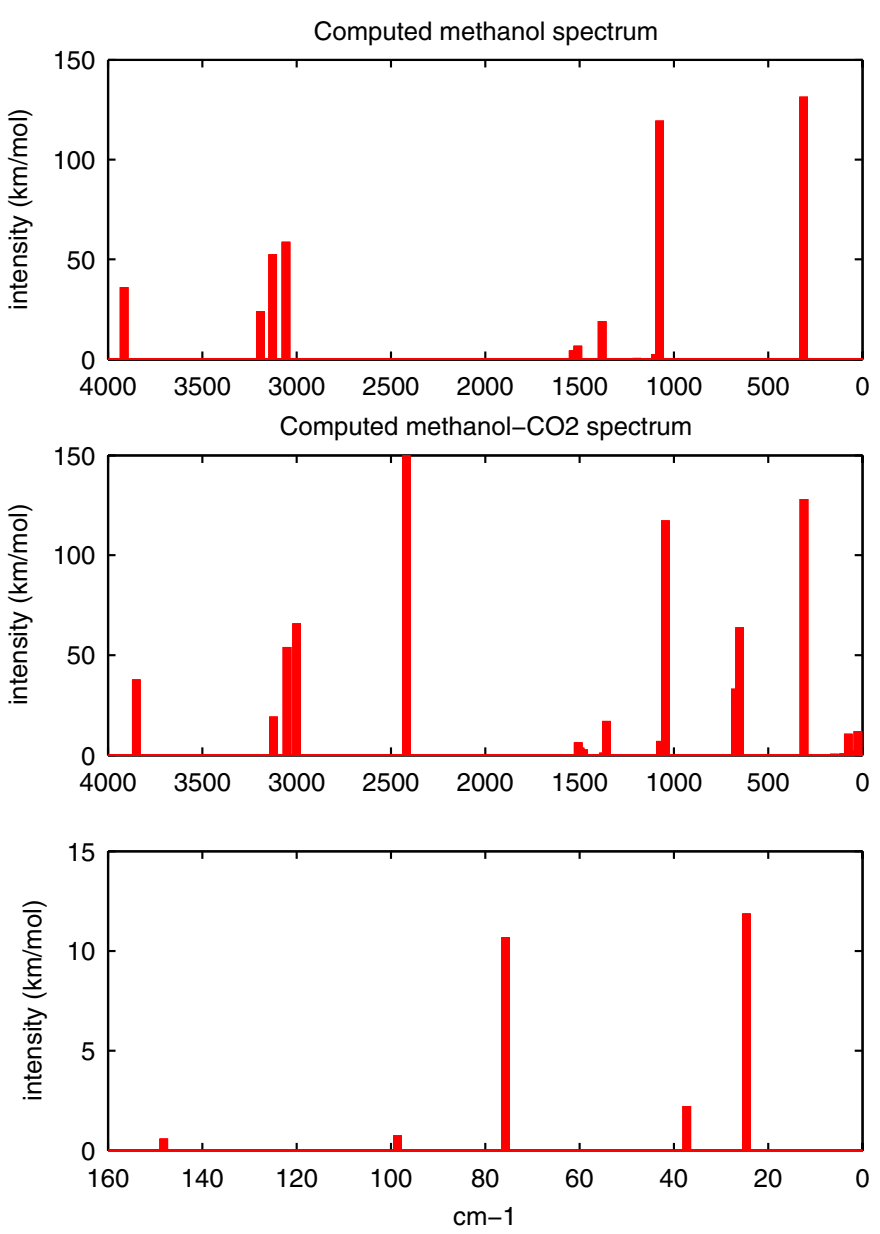

Fig. 4. A comparison between the computed spectra of the methanol monomer (top panel) and the complex $\mathrm{CO}_{2}: \mathrm{CH}_{3} \mathrm{OH}$ (middle panel). Bottom panel is a close up of the middle one, for the very low frequencies, showing the five complex specific bands and especialy the strongests near 24 and $75 \mathrm{~cm}^{-1}$. 


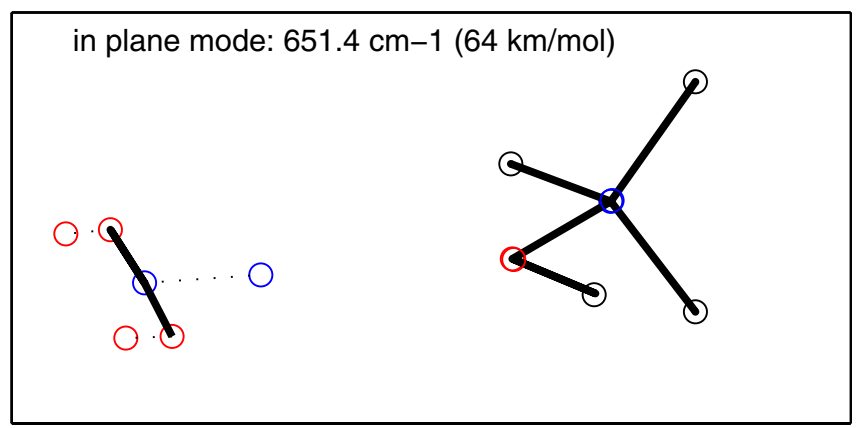

out of plane mode: $672.8 \mathrm{~cm}-1(33 \mathrm{~km} / \mathrm{mol})$

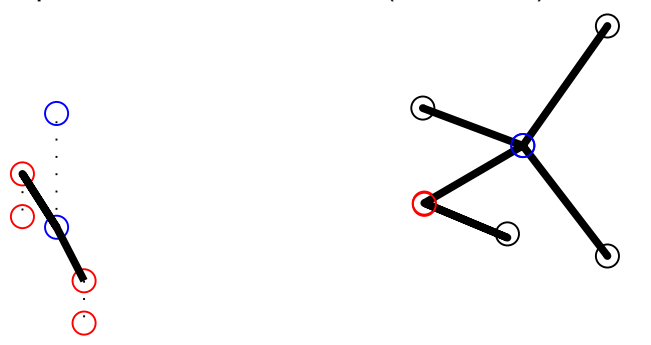

Fig. 5. The in-plane (top) and OOP (bottom) bending modes of $\mathrm{CO}_{2}$ complexed verticaly to the staggered methanol at B3LYP/6$311++\mathrm{G}^{* *}$ level (see Fig. 2 for conformation definitions). Dotted lines show direction atoms move when vibrating. IR intensities are indicated in parenthesis.

have intensities that could be observed in space. These wavelengths correspond to 132.6 and $414.8 \mu \mathrm{m}$ respectively and therefore only the former comes within the range investigated by the LWS onboard ISO. This band corresponds to a torsion around the $\mathrm{CO}$ axis with methanol turning one way and $\mathrm{CO}_{2}$ the other. We suggest that the appearance of this band in any future publications should be seen as a diagnostic of the formation of an intermolecular complex and the spectra should be interpreted accordingly.

\section{2. $\mathrm{CO}_{2}$ bending mode}

The calculated splittings of the $v_{2}$ bending mode were shown in Table 7 . The most astrophysically applicable values are those obtained using the B3LYP/6-311++G** method, which calculates a higher frequency band at $672.77 \mathrm{~cm}^{-1}$ and a lower frequency band at $651.36 \mathrm{~cm}^{-1}$ (with a split of $21.41 \mathrm{~cm}^{-1}$ ).

This split occurs because when the methanol is brought close to the $\mathrm{CO}_{2}$, the electric field of the $\mathrm{O}$ atom of methanol acts in the plane of the complex and opposes the in-plane bending mode. This change in the molecular environment alters the potential energy profile for this mode, and the vibration is shifted to lower frequency. Conversely, the out-of-plane bend is moved to higher frequency although with a smaller shift compared to the isolated $\mathrm{CO}_{2} v_{2}$ position $\left(667 \mathrm{~cm}^{-1}\right)$. Interestingly, the intensity of the in-plane mode is found to double while the OOP mode has a similar intensity to that observed for isolated $\mathrm{CO}_{2}$. The two $\mathrm{CO}_{2}$ bending modes are shown in Fig. 5. However a $1: 1$ interaction of methanol and $\mathrm{CO}_{2}$ is very unlikely to be the only complex in the ice matrix and indeed one
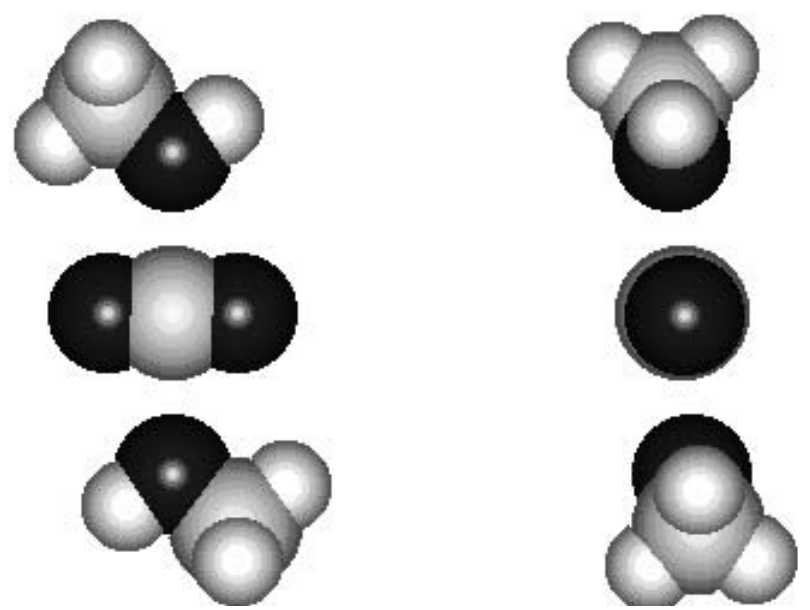

Fig. 6. Ball representation of the most stable conformer of $\mathrm{CH}_{3} \mathrm{OH}: \mathrm{CO}_{2}: \mathrm{CH}_{3} \mathrm{OH}$ complex. Different views of two methanols complexing to a central $\mathrm{CO}_{2}$ molecule.

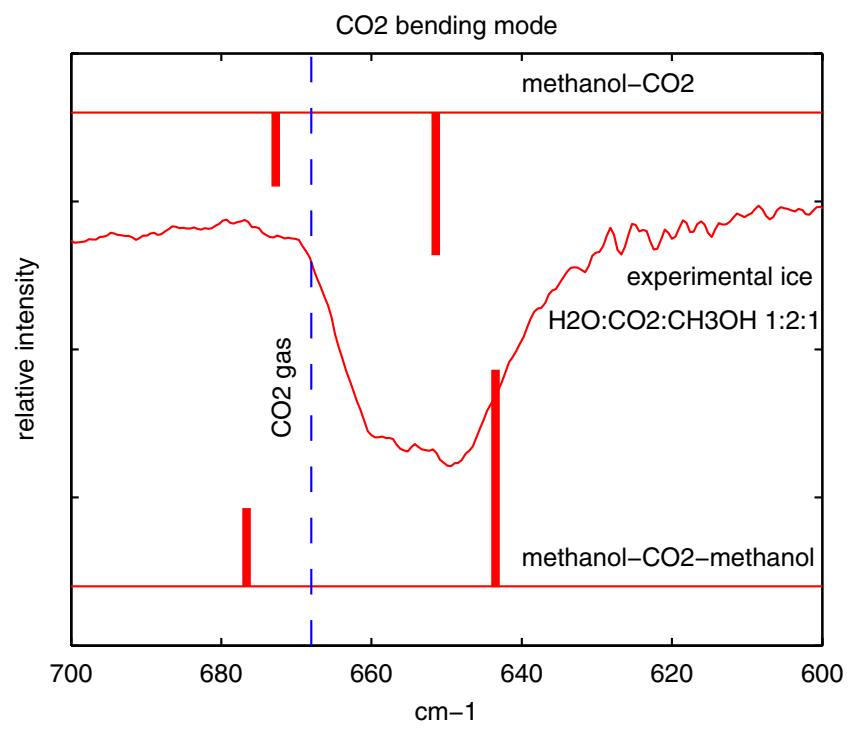

Fig. 7. A close-up of the calculated $\mathrm{CO}_{2}$ splitting at $\mathrm{B} 3 \mathrm{LYP} / 6$ $311++\mathrm{G}^{* *}$ level and comparison with an experimental ice analogue. It shows the maximum splitting of the trimer as well as the dimer.

might expect that the observed spectrum are representative of a number of different environments along the line of sight.

The possibility of an additional methanol interacting with the central $\mathrm{CO}_{2}$ molecule is the next logical progression and so the B3LYP/6-311++G** method was employed to investigate this alternative matrix environment. (The point group of the complex is $\mathrm{C}_{2 h}$ and two views of it are shown in Fig. 6). In the calculation negative frequencies appeared, which suggests that this is not the most stable conformation for the trimer. However, the results are still very instructive for comparative purposes. Figure 7 shows the area of interest for the $\mathrm{CO}_{2}$ bending mode and a comparison of the computed spectra of the two complexes with an experimental ice mixture of $\mathrm{H}_{2} \mathrm{O}: \mathrm{CO}_{2}: \mathrm{CH}_{3} \mathrm{OH}$ $(1: 2: 1)$ is shown.

From the previous discussion one would expect that the introduction of the second methanol would accentuate the splitting effects, as an additional electric field is acting in the plane 
of the complex. This is indeed what was observed with the inplane mode shifted to $643.48\left(89.9 \mathrm{~km} \mathrm{~mol}^{-1}\right)$ and the OOP mode to $676.65\left(32.4 \mathrm{~km} \mathrm{~mol}^{-1}\right)$. The subsequent splitting is therefore $33.17 \mathrm{~cm}^{-1}$ and represents the interaction that would produce the maximum splitting (Fig. 7). The multi-peak structure of the $\mathrm{CO}_{2}$ bending mode towards RAFGL 7009S would then represent a distribution of different matrix interactions in between the maximum and minimum frequencies for the methanol: $\mathrm{CO}_{2}(2: 1)$ complex.

\section{3. $\mathrm{CO}_{2}$ stretching modes}

Dartois et al. (1999b) proposed that a further observable consequence of the complex is the appearance of a weak new mode between $1300-1600 \mathrm{~cm}^{-1}$. This would correspond to the calculated intensity and the band again becomes forbidden for the trimer. Finally the antisymmetric $v_{3}$ stretch is not affected greatly by the interaction, either by a change in position or intensity. This again agrees with the observations of Dartois et al. (1999b) and is due to the fact that the $\mathrm{CO}_{2}$ molecule tends to position itself at right angle to the axis defined by the Lewis acid bond.

\subsection{Methanol specific features}

Figure 8 shows a comparison of three spectra. The top one reveals the spectrum computed for a single methanol monomer again with the B3LYP/6-311++ $\mathrm{G}^{* *}$ method. Underneath are laboratory spectrum recorded at IAS. The solid line represents methanol in the gas phase and the dashed line is amorphous solid methanol. The difference between the two is very instructive as regards the applicability of the calculations to IS ices. To try to reproduce the methanol environment in the amorphous ice, the same method was used to calculate frequencies for a dimer of two methanol molecules $\left(\mathrm{C}_{\mathrm{s}}\right.$ point group $)$ and the resultant spectrum is shown in the bottom panel. Again the calculations showed negative frequencies, which means that it is not the most stable methanol dimer. However, it is important as it illustrates several general points. Firstly, it is interesting to note that the experimental spectra show a large shift in the position of the $\mathrm{OH}$ stretch in the solid methanol compared to the gaseous spectrum. Similarly it can be seen that, for the calculated methanol dimer, the $\mathrm{OH}$ stretch is shifted to longer wavelengths as a result of the hydrogen bonding interaction. From this we propose that the monomer methanol calculation should be compared to the experimental gas phase spectrum, whereas the dimer reproduces the solid state features more accurately. There are also new bands predicted for the dimer spectrum at low frequencies (Fig. 8). These could explain the fact that the predicted band at around $297.16 \mathrm{~cm}^{-1}$ appears as a hump at around $600 \mathrm{~cm}^{-1}$ in the solid spectrum.

\section{Conclusion}

The calculations in this paper followed on from a paper by Jamróz et al. (1995), which investigated various EDA complexes involving $\mathrm{CO}_{2}$, using the $\mathrm{RHF} / 3-21 \mathrm{G}^{*}$ method. The effect of extending the basis set and using methods that include
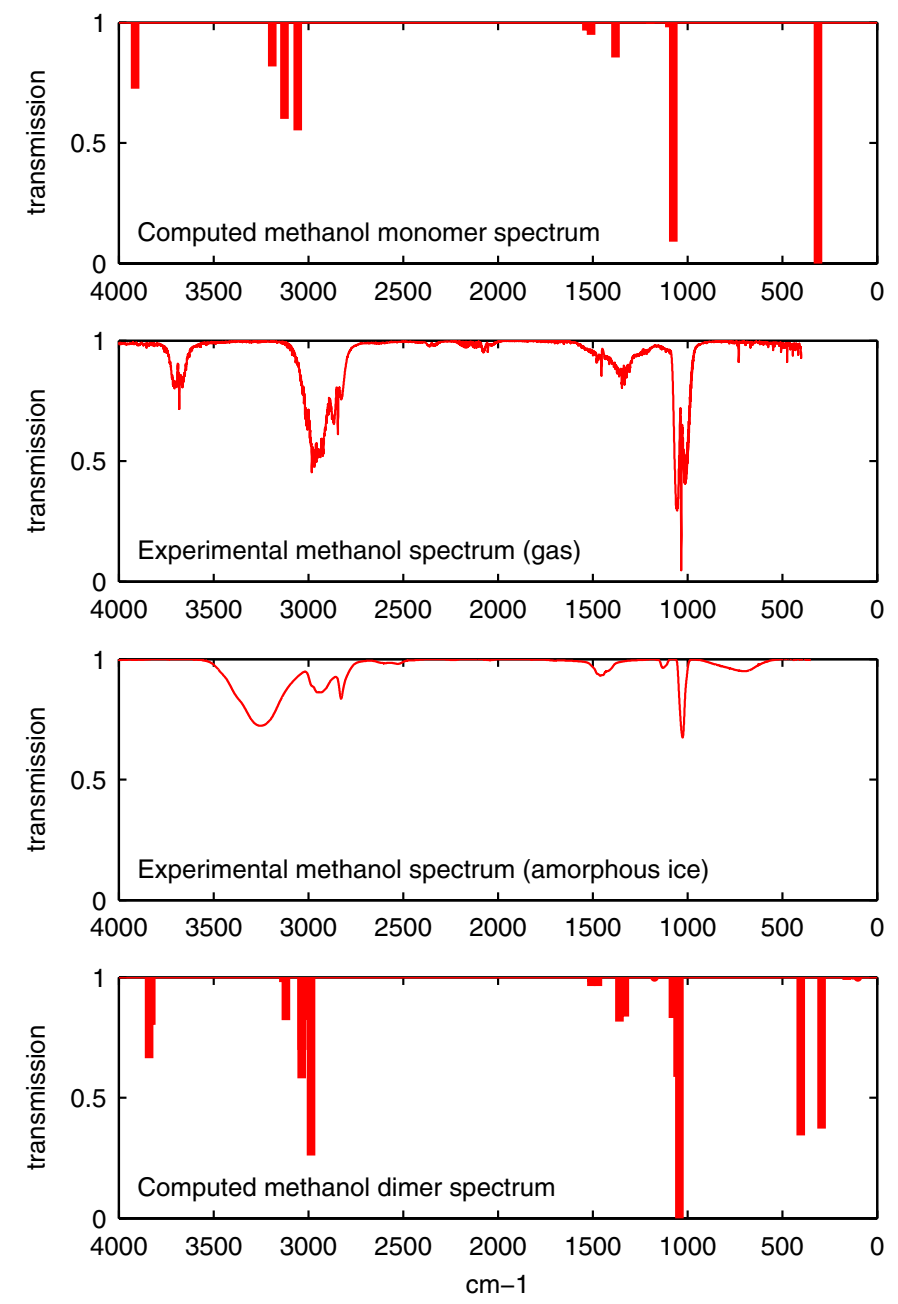

Fig. 8. Computed methanol spectra (monomer and dimer) and comparison with experimental gas and solid phase spectra.

electron correlation effects has been seen. Calculated frequencies have been obtained for isolated $\mathrm{CO}_{2}$ and methanol and their respective dimers. In addition, the complex that is proposed to explain the observed splitting of the $v_{2} \mathrm{CO}_{2}$ bending mode in IS ices has been investigated. Finally, results for a complex involving two methanol molecules complexing to a central $\mathrm{CO}_{2}$ molecule have also been presented. It has been found that the B3LYP hybrid method using the 6$311++\mathrm{G}^{* *}$ basis set, is the best for calculating frequencies in agreement with laboratory and interstellar spectra. By comparison with laboratory spectra it has been shown that calculations involving a single methanol should be compared to laboratory gas phase spectra, whereas the dimer calculations reproduce the solid state spectra more accurately. For the EDA complex, the splitting of the $v_{2} \mathrm{CO}_{2}$ bending mode is found to be $21.31 \mathrm{~cm}^{-1}$ with one methanol complexed and this increases to $33.17 \mathrm{~cm}^{-1}$ when the second methanol is introduced. The multi-peak structure in the bending mode, observed towards young protostars (e.g. RAFGL 7009S), will then represent a distribution of different matrix interactions in between the maximum and minimum frequencies for the methanol: $\mathrm{CO}_{2}$ (2:1) complex. The symmetric stretching vibration, which is forbidden in the isolated $\mathrm{CO}_{2}$ molecule, becomes slightly 
active when the methanol complexes to it, with this weak new mode appearing at around $1372 \mathrm{~cm}^{-1}$. Instruments are becoming increasingly sensitive and in the future will provide spatial information to further explain the structure of the ice matrix. Modes that are specific to complex formation include one at $75.42 \mathrm{~cm}^{-1}(132.6 \mu \mathrm{m})$, which falls within the spectral range of the LWS aboard ISO. We propose that future observation of this band should be seen as a diagnostic of the intermolecular complex between $\mathrm{CO}_{2}$ and methanol.

Acknowledgements. Authors would thanks C. Marsden (IRSAMC), L. d'Hendecourt (IAS) and K. Demyk (IAS) for their direct and indirect contributions.

\section{References}

Allamandola, L. J. 1987, J. Mol. Struct., 157, 255

Baratta, G. A., Palumbo, M. E., \& Strazzulla, G. 2000, A\&A, 357, 1045

Becke, A. D. 1992, J. Chem. Phys., 97, 9173

Bohren, C. F., \& Huffman, D. R. 1983, in Absorption and scattering of light by small particles (New York: John Wiley)

Chiar, J. E., Adamson, A. J., \& Whittet, D. C. B. 1996, ApJ, 472, 665

Cox, P. 1989, A\&A, 225, L1

Dartois, E., d'Hendecourt, L., Boulanger, F., et al. 1998, A\&A, 331, 651
Dartois, E., Schutte, W., Geballe, T. R., et al. 1999a, A\&A, 342, L32

Dartois, E., Demyk, K., d'Hendecourt, L., \& Ehrenfreund, P. 1999b, A\&A, 351, 1066

DeGraauw, T., Whittet, D. C. B., Gerakines, P. A., et al. 1996, A\&A, $315, \mathrm{~L} 345$

d'Hendecourt, L., Jourdain de Muizon, M., Dartois, E., et al. 1996, A\&A, 315, L365

Ehrenfreund, P., Dartois, E., Demyk, K., \& d'Hendecourt, L. 1998, A\&A, 339, L17

Ehrenfreund, P., Kerkhof, O., Schutte, W.A., et al. 1999, A\&A, 350, 240

Frisch, M. J., et al. 1998, GAUSSIAN 98 (Rev. A.7, Pittsburgh: Gaussian, Inc.)

Jamróz, M. H., Dowbrowolski, J. C., Bajdor, K., \& Borowiak, M. A. 1995, J. Mol. Struct., 349, 9

Kazarian, S. G., Vincent, M. F., Bright, F. V., Liotta, C. L., \& Eckert, C. A. 1996, J. Am. Chem. Soc., 118, 1729

Lee, A., Yang, W., \& Parr, R. G. 1988, Phys. Rev. B, 37, 785

Lide, D. (editor in chief) 1992, in Handbook of Chemistry and Physics (CRC Press)

Palumbo, M. E., Baratta, G. A., Brucato, J. R., et al. 1998, A\&A, 334, 247

Pontoppidan, K. M., Dartois, E., van Dishoeck, E. F., Thi, W., \& d'Hendecourt, L. 2003, A\&A, 404, L17

Shimanouchi, T. 1972, Tables of molecular vibrational frequencies, Nat. Bur. Stand. 